\title{
Organobase-catalyzed Hydroxyl-yne Click Polymerization
}

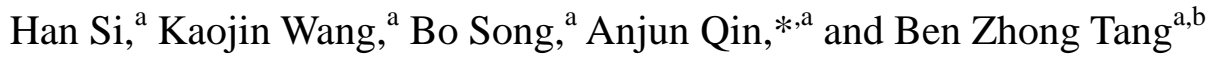

${ }^{a}$ State Key Laboratory of Luminescent Materials and Devices, Key Laboratory of

Luminescence from Molecular Aggregates of Guangdong Province, Center for Aggregation-Induced Emission, South China University of Technology, Guangzhou 510640, China

${ }^{b}$ Department of Chemistry, Hong Kong Branch of Chinese National Engineering Research Centre for Tissue Restoration and Reconstruction, Institute for Advanced Study, and Department of Chemical and Biological Engineering, The Hong Kong University of Science \& Technology (HKUST), Clear Water Bay, Kowloon, Hong Kong, China 


\section{ABSTRACT}

The proposition of click chemistry has provided a quick channel for saccharides modification, which has always been worth exploring. Click reaction of hydroxyl groups possessed by saccharides is thus highly desirable to be developed. In this paper, we report hydroxyl-yne click polymerization using ester activated alkynes and alcoholic hydroxyl groups. The polymers, poly(vinyl ether ester)s (PVEEs), were obtained with high weight-average molecular weights up to 71000 were obtained in excellent yields up to $99 \%$ using a commercially organic base of bicyclo[2.2.2]-1,4-diazaotane (DABCO) as catalyst under ambient conditions. The obtained polymers possess high thermal stability and low cytotoxicity. Both semi-crystalline and amorphous polymers were obtained due to the different flexibility of monomers. Upon incorporating aggregation-induced emission (AIE) moiety of tetraphenylethylene (TPE), the resultant polymers displayed typical AIE characteristics. This work provides a potential strategy for saccharides modification via the hydroxyl-yne click reaction. 


\section{INTRODUCTION}

Saccharides are the most abundant organic molecules in nature and can be synthesized and metabolized by almost all of organisms all the time. ${ }^{1}$ Although there are countless kinds of saccharides, such as monosaccharides, oligosaccharides and polysaccharides, the monosaccharides or oligosaccharides could combine infinitely by glycosylation..$^{2-4}$ Saccharides have been successfully applied in biological filed via glycobiology. ${ }^{5-8}$ They are not only the main energy source for most organisms, but they are also important in carrying and transmitting information. Since the role of saccharides is diverse, effective use of saccharides is particularly important. Although there are still some problems, the research on glycobiology has obtained certain achievements. $^{9-11}$ In terms of the chemical structure, the saccharides are polyhydroxyl aldehydes or ketones and thus have their commonality. In general, the modification reactions of saccharides can be classified into esterification, acetylation, ${ }^{12-17}$ deprotection, ${ }^{18}$ methylation, ${ }^{19}$ dehydration, reduction, ${ }^{20-24}$ etc. More high efficient and practical modification reactions of saccharides are urgent.

Click chemistry provides a new alternative for saccharides modification. A typical click reaction, azide-alkyne cycloaddition reaction has been successfully used to modify saccharides, ${ }^{25-29}$ in which ethynyl or azide functional groups, however, are needed to be introduced. Therefore, the direct modification reactions to the hydroxyl functional groups of saccharides have been investigated. For example, the polymerization of commercial monomers containing hydroxyl groups such as hexanediol or phenol was studied. Jiang reported that diacrylates and diols were 
catalyzed by $t$ - $\mathrm{BuP}_{2}$ under mild conditions to form degradable poly(ester-ether)s, which would have widely applicable as bifunctional materials. ${ }^{30}$

In recent years, the alkyne-based click polymerizations have drawn tremendous attention. Our group developed the azide-alkyne, thiol-alkyne, and amine-yne click polymerizations based on the carbon-carbon triple-bond building blocks. ${ }^{31-42}$ In 2016, the alkyne polyannulation of diphenols and internal diynes catalyzed by palladium was polymerized successfully. However, it needs high reaction temperature and different metal catalysts (e.g., palladium, silver, and copper), which are hard to be completely removed. 4,4'-Sulfonyldiphenol could only be used as polymerization monomer, limiting the scope of the polymerization. ${ }^{38}$ Aromatic alkynes and diols were also polymerized in the presence of superbase catalyzation, which also needs high temperature and nitrogen protection. $^{39}$ Subsequently, the activated bis(aroylacetylene)s and diphenols were used to carry out the click polymerization using organic base 4-dimethylaminopyridine (DMAP) at $40{ }^{\circ} \mathrm{C} .{ }^{40}$ The above researches either are based on phenolic hydroxyl groups or need rigorous conditions. However, report on the polymerization of more common alcoholic hydroxyl groups and activated diynes in a metal-free fashion under mild conditions is rare.

Fortunately, inspired by the reaction of alcohol and ester activated alkynes, ${ }^{43}$ we developed an efficient click polymerization of ester activated alkynes and diols in the presence of the catalyst of a commonly used organic base DABCO under mild conditions without the need of nitrogen protection. The resulted poly(vinylene ether ester)s (PVEEs) possess high thermal stability with decomposition temperature $\left(T_{\mathrm{d}}\right)$ 
above $300{ }^{\circ} \mathrm{C}$. Polymers obtained by the polymerization of alcoholic diols and diynes monomers are crystallizable. Due to the lack of cytotoxicity, these polymers may have promising applications in the biological field. Their photophysical properties and application in explosive detection were also studied.

\section{Scheme 1. Click Polymerization of Diynes 1 and Diols 2}

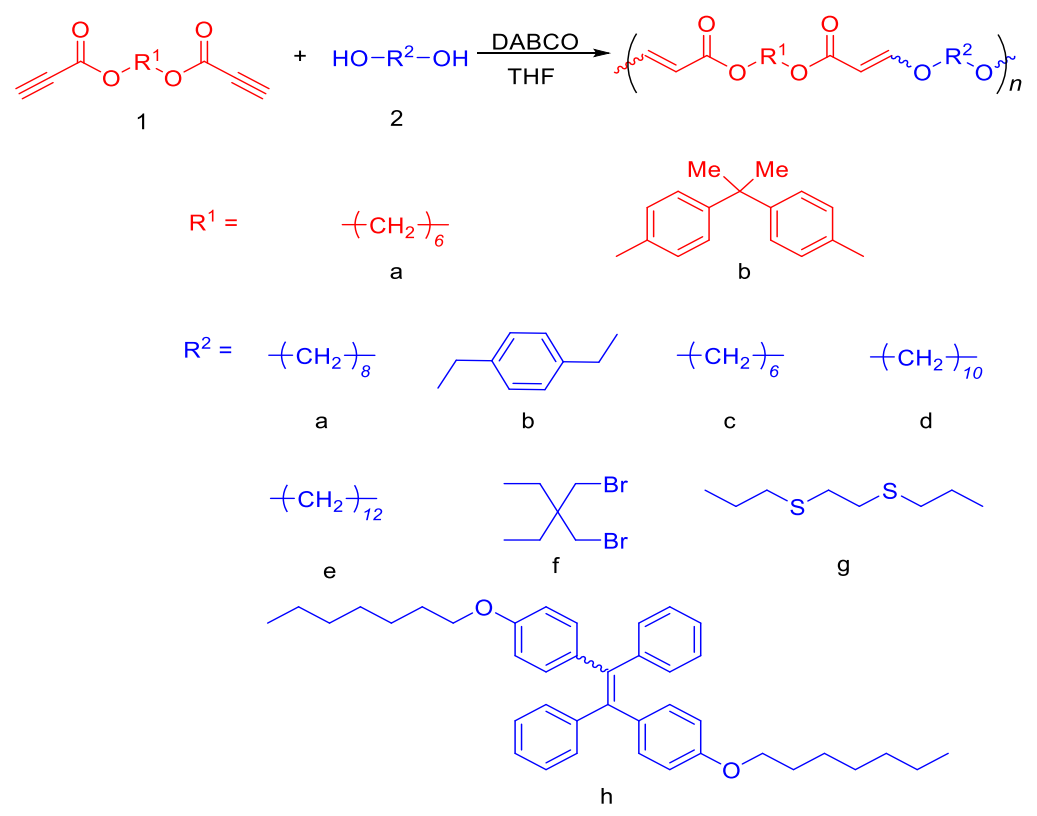

\section{RESULTS AND DISCUSSION}

Polymerization. All the monomers are commercially available or can be synthesized easily. In order to obtain polymers with high weight-average molecular weight $\left(M_{\mathrm{w}}\right)$ and good solubility, diyne $\mathbf{1 a}$ and diol $\mathbf{2 a}$ were used as model monomers to optimize the polymerization conditions.

The polymerization time was first studied. As shown in Table 1, the polymer with a high $M_{\mathrm{w}}(15500)$ were obtained in an ideal yield in $98 \%$ after only $1 \mathrm{~h}$. No change was observed when the reaction time was extended. Thus, we chose $1 \mathrm{~h}$ as the optimized polymerization time. 
Table 1. Time course of the polymerization of $1 \mathrm{a}$ and $2 \mathrm{a}^{a}$

\begin{tabular}{ccccc}
\hline entry & $t(\mathrm{~h})$ & yield $(\%)$ & $M_{\mathrm{w}}{ }^{b}$ & $\oplus^{b}$ \\
\hline 1 & 0.5 & 92 & 13900 & 2.31 \\
2 & 1.0 & 98 & 15500 & 2.27 \\
3 & 2.0 & 98 & 15700 & 2.32 \\
4 & 3.0 & 99 & 15500 & 2.24 \\
\hline
\end{tabular}

${ }^{a}$ Carried out in THF at $25{ }^{\circ} \mathrm{C}$ under air in the presence of DABCO. $[\mathbf{1 a}]=[\mathbf{2 a}]=0.20 \mathrm{M},[\mathrm{DABCO}]=$ 0.020 M. ${ }^{b}$ Estimated by APC in THF on the basis of a polystyrene (PS) calibration; $M_{\mathrm{w}}=$ weight-average molecular weight; $D=$ polydispersity index $\left(M_{\mathrm{w}} / M_{\mathrm{n}}, M_{\mathrm{n}}=\right.$ number-average molecular weight).

The effect of solvents on the polymerization was then investigated. As shown in Table 2, the highest $M_{\mathrm{w}}$ of 14700 and a $97 \%$ yield were obtained in THF, while the highest yield of $99 \%$ and an $M_{\mathrm{w}}$ of 10900 were achieved in DCM. Although the polymerization processed smoothly both in THF and DCM, the solubility of the diols in DCM is lower than in THF, which is unbenifited for the reaction. Therefore, THF was selected as the optimized polymerization solvent.

Table 2. Effect of solvent on the polymerization of $1 \mathrm{a}$ and $2 \mathrm{a}^{a}$

\begin{tabular}{ccccc}
\hline entry & solvent & yield $(\%)$ & $M_{\mathrm{w}}{ }^{b}$ & $D^{b}$ \\
\hline 1 & THF & 97 & 14700 & 2.25 \\
2 & DMF & 85 & 5600 & 1.57 \\
3 & DMSO & 91 & 3400 & 1.62 \\
4 & DCM & 99 & 10900 & 1.74 \\
5 & $\mathrm{CHCl}_{3}$ & 59 & 2100 & 1.16 \\
\hline
\end{tabular}

${ }^{a}$ Carried out at $25{ }^{\circ} \mathrm{C}$ under air in the presence of DABCO for $1 \mathrm{~h}$. $[\mathbf{1 a}]=[\mathbf{2 a}]=0.20 \mathrm{M}$, $[\mathrm{DABCO}]=0.020 \mathrm{M} .{ }^{b}$ Estimated by APC in THF on the basis of a PS calibration; $M_{\mathrm{w}}=$ weight-average molecular weight; $\oslash=$ polydispersity index $\left(M_{\mathrm{w}} / M_{\mathrm{n}}, M_{\mathrm{n}}=\right.$ number-average molecular weight). 
The effect of monomer concentration on the polymerization was also explored. As shown in Table $3, M_{\mathrm{w}}$ of the polymers increased with increasing the monomer concentrations from 0.1 to $0.4 \mathrm{M}$, while yields of the products were nearly unchanged. The optimal $M_{\mathrm{w}}$ of 33900 with a $95 \%$ yield was obtained when the monomer concentration is $0.4 \mathrm{M}$.

Table 3. Effect of monomer concentration on the polymerization of $1 \mathrm{a}$ and $2 \mathrm{a}^{a}$

\begin{tabular}{ccccc}
\hline entry & {$[\mathrm{M}]$} & yield $(\%)$ & $M_{\mathrm{w}}{ }^{b}$ & $\bigoplus^{b}$ \\
\hline 1 & 0.4 & 95 & 33900 & 2.35 \\
2 & 0.3 & 94 & 32700 & 2.90 \\
3 & 0.2 & 96 & 16100 & 2.21 \\
4 & 0.1 & 96 & 8800 & 2.11 \\
\hline
\end{tabular}

${ }^{a}$ Carried out in THF at $25^{\circ} \mathrm{C}$ under air in the presence of DABCO for $1 \mathrm{~h} .{ }^{b}$ Estimated by APC in THF on the basis of a PS calibration; $M_{\mathrm{w}}=$ weight-average molecular weight; $D=$ polydispersity index $\left(M_{\mathrm{w}} / M_{\mathrm{n}}, M_{\mathrm{n}}=\right.$ number-average molecular weight $)$.

Afterward, we studied the effect of DABCO amount on the click polymerization (Table 4). With the increase of catalyst concentration, polymer yields did not change much, while $M_{\mathrm{w}}$ values increased gradually. To balance molecular weight and catalyst concentration, $0.04 \mathrm{M} \mathrm{DABCO}$ was chosen as the polymerization catalyst concentration. It is worth noting that DABCO could be removed simply by the precipitation.

Finally, the effect of the reaction temperature on the click polymerization was studied, and the results are shown in Table 5. The polymerization efficiency showed a significant decrease with an increase of temperature. $M_{\mathrm{w}}$ was reduced from 32400 to 25000 , and polymer yield was also decreased from 94 to $85 \%$ with an increase of 
polymerization temperature from 25 to $60{ }^{\circ} \mathrm{C}$. Therefore, we used $25{ }^{\circ} \mathrm{C}$ as the polymerization temperature.

Table 4. Effect of catalyst concentration on the polymerization of 1a and $2 a^{a}$

\begin{tabular}{ccccc}
\hline entry & {$[\mathrm{DABCO}] /[\mathbf{1 a}]$} & yield $(\%)$ & $M_{\mathrm{w}}{ }^{b}$ & $D^{b}$ \\
\hline 1 & 0.05 & 94 & 24200 & 2.57 \\
2 & 0.10 & 94 & 31600 & 2.65 \\
3 & 0.15 & 83 & 35700 & 2.57 \\
4 & 0.20 & 93 & 39900 & 2.59 \\
\hline
\end{tabular}

${ }^{a}$ Carried out in THF at $25{ }^{\circ} \mathrm{C}$ under air in the presence of DABCO for $1 \mathrm{~h}$. $[\mathbf{1 a}]=[\mathbf{2 a}]=0.40 \mathrm{M} .{ }^{b}$ Estimated by APC in THF on the basis of a PS calibration; $M_{\mathrm{w}}=$ weight-average molecular weight; $\oslash=$ polydispersity index $\left(M_{\mathrm{w}} / M_{\mathrm{n}}, M_{\mathrm{n}}=\right.$ number-average molecular weight).

Table 5. Effect of temperature on the polymerization of $1 \mathrm{a}$ and $2 \mathrm{a}^{a}$

\begin{tabular}{ccccc}
\hline entry & $T\left({ }^{\circ} \mathrm{C}\right)$ & yield $(\%)$ & $M_{\mathrm{w}}{ }^{b}$ & $Ð^{b}$ \\
\hline 1 & 25 & 94 & 32400 & 2.51 \\
2 & 40 & 98 & 26500 & 2.30 \\
3 & 60 & 85 & 25000 & 2.35 \\
\hline
\end{tabular}

${ }^{a}$ Carried out in THF under air in the presence of DABCO. $[\mathbf{1 a}]=[\mathbf{2 a}]=0.40 \mathrm{M},[\mathrm{DABCO}]=0.040 \mathrm{M}$.

${ }^{b}$ Estimated by APC in THF on the basis of a polystyrene (PS) calibration; $M_{\mathrm{w}}=$ weight-average molecular weight; $Ð=$ polydispersity index $\left(M_{\mathrm{w}} / M_{\mathrm{n}}, M_{\mathrm{n}}=\right.$ number-average molecular weight $)$.

The other diynes and diols were performed to verify the universality and robustness of DABCO-mediated click polymerization by the use of the optimized polymerization conditions. The results showed that the polymerizations propagated smoothly, and the polymers P1a2a-P1b2a with high $M_{\mathrm{w}}$ values (up to 71000 ) were produced in excellent yields (up to 99\%) (Table 6). 
Table 6 Polymerizations of diols and diynes ${ }^{a}$

\begin{tabular}{cccccccc}
\hline entry & monomer & polymer & yield $(\%)$ & $M_{\mathrm{w}}{ }^{b}$ & $\Xi^{b}$ & $T_{\mathrm{m}}\left({ }^{\circ} \mathrm{C}\right)$ & $\Delta H_{\mathrm{m}}(\mathrm{J} / \mathrm{g})$ \\
\hline 1 & $\mathbf{1 a + 2 a}$ & P1a2a & 96 & 32500 & 2.99 & 114.2 & 62.17 \\
2 & $\mathbf{1 a + 2 b}$ & P1a2b & 99 & $6400^{c}$ & $2.09^{c}$ & $135.5,159.9^{d}$ & 62.16 \\
3 & $\mathbf{1 a + 2 c}$ & P1a2c & 99 & $7600^{c}$ & $1.71^{c}$ & 132.7 & 72.16 \\
4 & $\mathbf{1 a + 2 d}$ & P1a2d & 97 & 32300 & 2.27 & 90.2 & 44.07 \\
5 & $\mathbf{1 a + 2 e}$ & P1a2e & 99 & 33000 & 2.38 & 101.5 & 66.85 \\
6 & $\mathbf{1 a + 2 f}$ & P1a2f & 94 & 32000 & 2.39 & - & - \\
7 & $\mathbf{1 a + 2 g}$ & P1a2g & 77 & 57600 & 2.64 & $55.9,63.7^{d}$ & 48.82 \\
8 & $\mathbf{1 a + 2 h}$ & P1a2h & 99 & 71000 & 2.04 & - & - \\
9 & $\mathbf{1 b + 2 a}$ & P1b2a & 99 & 21700 & 1.91 & - & - \\
\hline
\end{tabular}

${ }^{a}$ Carried out in THF at $25{ }^{\circ} \mathrm{C}$ under air in the presence of DABCO. $[1]=[2]=0.40 \mathrm{M},[\mathrm{DABCO}]=$ $0.040 \mathrm{M} .{ }^{b}$ Estimated by APC in THF on the basis of a PS calibration; $M_{\mathrm{w}}=$ weight-average molecular weight; $Ð=$ polydispersity index $\left(M_{\mathrm{w}} / M_{\mathrm{n}}, M_{\mathrm{n}}=\right.$ number-average molecular weight $) .{ }^{c}$ Partially soluble in THF. ${ }^{d}$ Two separated melting peaks.

Structure Characterization. A series of PVEEs P1a2a-P1b2a were obtained by our developed click polymerization. Most polymers can be dissolved well in common solvents. Fourier transformed infrared spectroscopy (FT-IR) and nuclear magnetic resonance (NMR) were used to characterize their structures (Figures 1-3 and S1-S3). Meanwhile, to assist the structural characterization of the polymers, the model compound M1 was prepared using the same conditions as the polymerization reaction (Scheme S6).

Figure 1 shows FT-IR spectra of compound 1a, 2a, model molecular M1, and polymer P1a2a. The absorption peak of 1a associated with $\equiv \mathrm{C}-\mathrm{H}$ and $\mathrm{C} \equiv \mathrm{C}$ stretching vibrations are observed at 3228 and $2112 \mathrm{~cm}^{-1}$, respectively. A strong absorption band at $3376 \mathrm{~cm}^{-1}$ is ascribed to the stretching vibrations of hydroxyl group in $\mathbf{2 a}$. However, 
these characteristic peaks disappeared, and the absorption band of $\mathrm{C}=\mathrm{C}$ stretching vibration appeared at $1638 \mathrm{~cm}^{-1}$ appeared for P1a2a, indicating that the ethynyl groups of $\mathbf{1 a}$ and the hydroxyl groups of $\mathbf{2 a}$ were consumed completely by the polymerization. Similar results were observed for $\mathbf{M 1}$ and other polymers P1a2b-P1b2a (Figure S1).

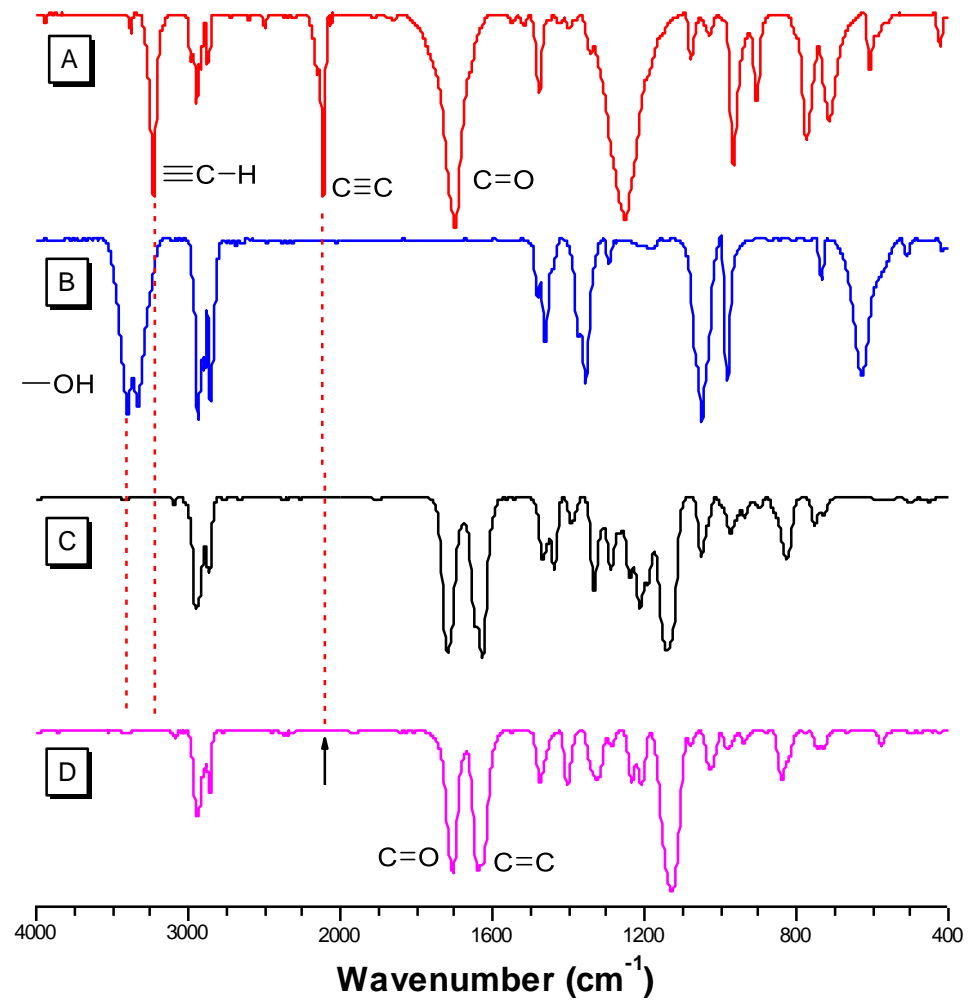

Figure 1. FT-IR spectra of (A) 1a, (B) 2a, (C) model compound M1 and (D) polymer P1a2a.

To further verify polymer structures, ${ }^{1} \mathrm{H}$ NMR and ${ }^{13} \mathrm{C}$ NMR were also measured. ${ }^{1} \mathrm{H}$ NMR spectra of 1a, 2a, model compound M1 and polymer P1a2a are shown in Figure 2. The ethynyl protons 1a were observed at $2.88 \mathrm{ppm}$. The hydroxyl characteristic protons of $\mathbf{2 a}$ in $\mathrm{CDCl}_{3}$ was not observed, because they may weaken or even disappear in $\mathrm{CDCl}_{3}$. The signal assigned to vinyl protons of $\mathbf{M 1}$ appeared at 7.59 and $5.19 \mathrm{ppm}$, respectively. The P1a2a also showed the signals of vinyl protons at 
7.58 and 5.17 ppm. $^{40,44}$ Similar ${ }^{1} \mathrm{H}$ NMR spectra were obtained for other PVEEs (Figures S2 and S3). Interestingly, the polymers containing aliphatic chains only show $E$-isomeric configuration, while P1b2a showed a Z/E configuration. A transesterification also occurred when P1b2a was polymerized. By calculating the integral area of NMR, the ratio of transesterification was about $7 \% .^{44}$
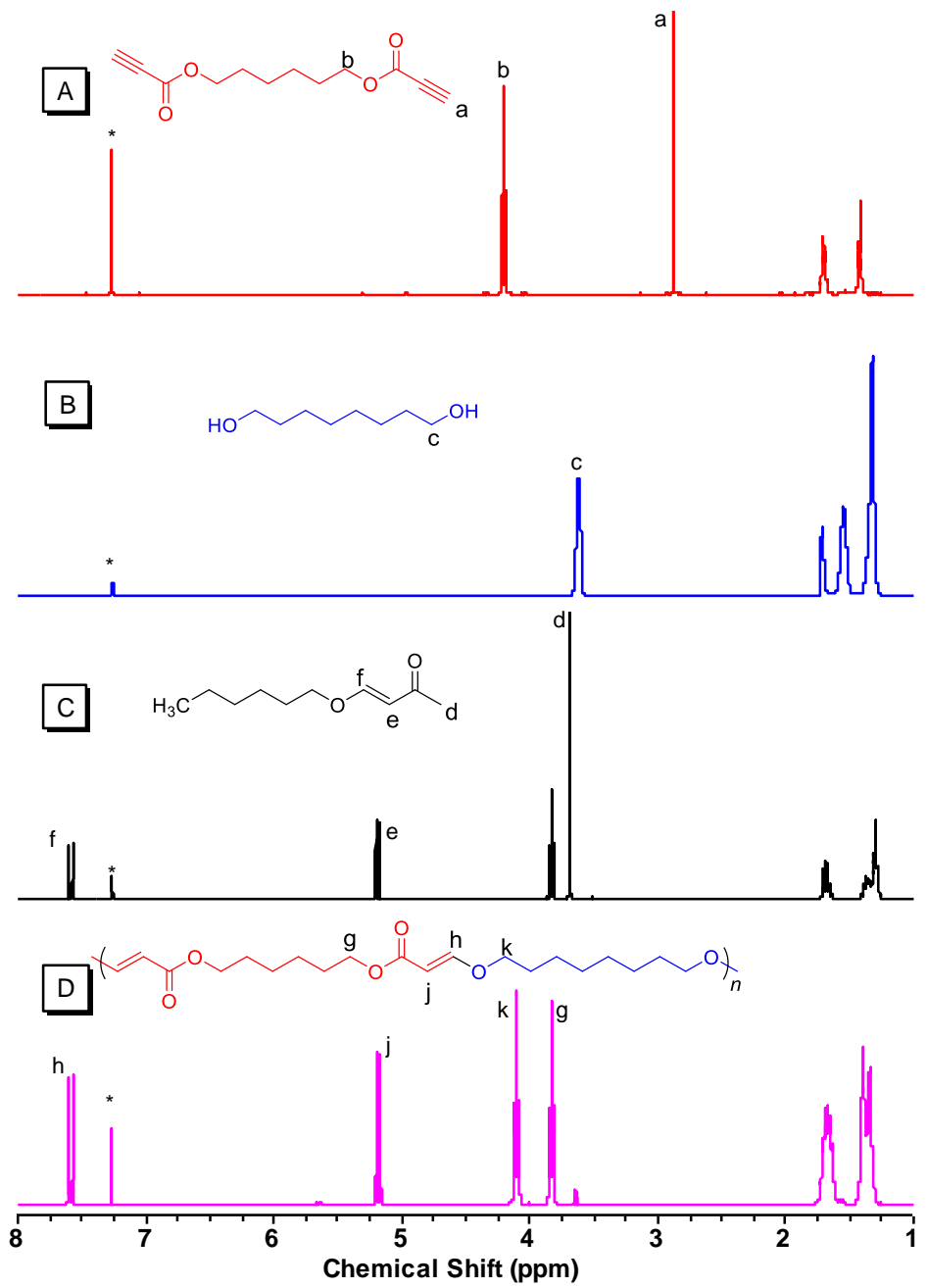

Figure 2. ${ }^{1} \mathrm{H}$ NMR spectra of $1 \mathbf{a}(\mathrm{A}), \mathbf{2 a}(\mathrm{B}), \mathbf{M 1}(\mathrm{C})$, and P1a2a (D) in $\mathrm{CDCl}_{3}$. The solvent peaks are marked with asterisks.

The ${ }^{13} \mathrm{C}$ NMR spectrum further substantiate the conclusions drawn from ${ }^{1} \mathrm{H}$ NMR spectral analysis (Figure 3). The resonance peaks of the carbon atom of the ethynyl group at 74.86 and 74.69 ppm disappeared in the spectra of P1a2a, suggesting that it 
was completely converted by the reaction. Meanwhile, new peaks associated with vinyl carbon atoms of M1 and P1a2a appeared at 162.68 and $96.38 \mathrm{ppm}$. Similar results were observed for P1a2b-P1b2a (Figures S4 and S5).

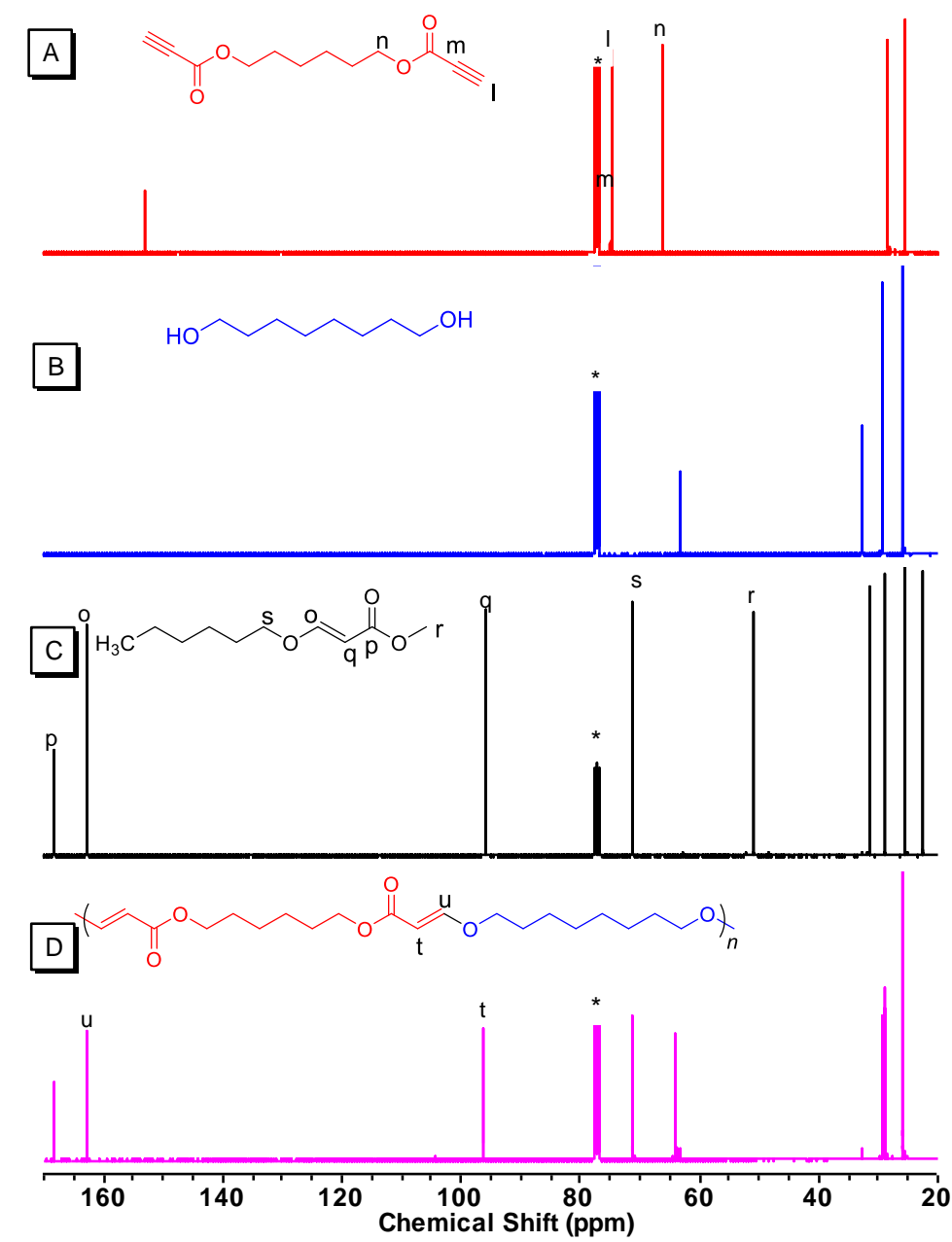

Figure 3. ${ }^{13} \mathrm{C}$ NMR spectra of $1 \mathbf{a}(\mathrm{A}), \mathbf{2 a}(\mathrm{B}), \mathbf{M 1}(\mathrm{C})$, and P1a2a (D) in $\mathrm{CDCl}_{3}$. The solvent peaks are marked with asterisks.

Thermal properties of the resultant polymers. The resultant polymers are soluble in commonly used organic solvents, such as $N, N$-dimethylformamide (DMF), dimethyl sulfoxide (DMSO), dichloromethane (DCM), and ethyl acetate (EA). Their thermal stability was measured by TGA (Figure 4$). T_{\mathrm{d}}$ values (5\% weight loss) of all polymers are above $300{ }^{\circ} \mathrm{C}$, suggesting that they have excellent thermal stability. 


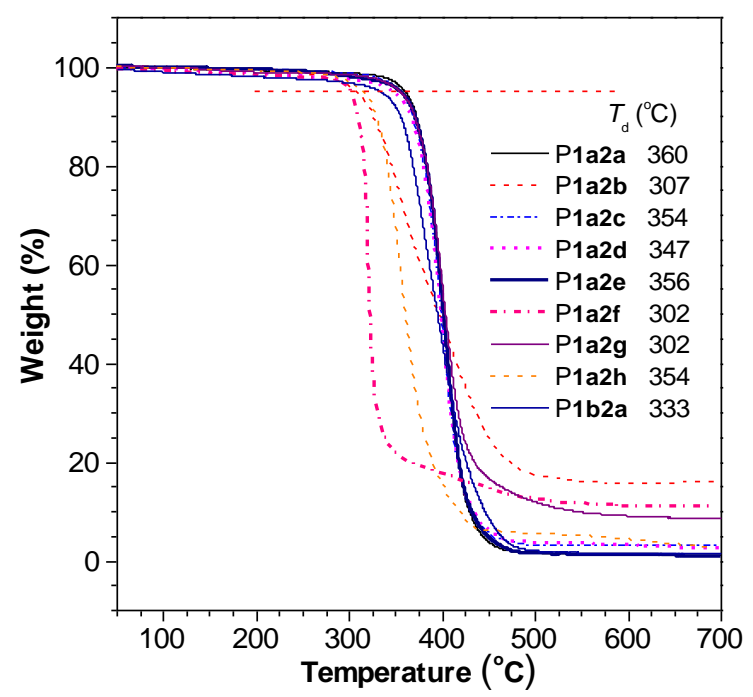

Figure 4. Thermogravimetric analysis (TGA) thermograms of P1a2a-P1b2a. $T_{\mathrm{d}}$ represents the temperature of $5 \%$ weight loss of the polymers.
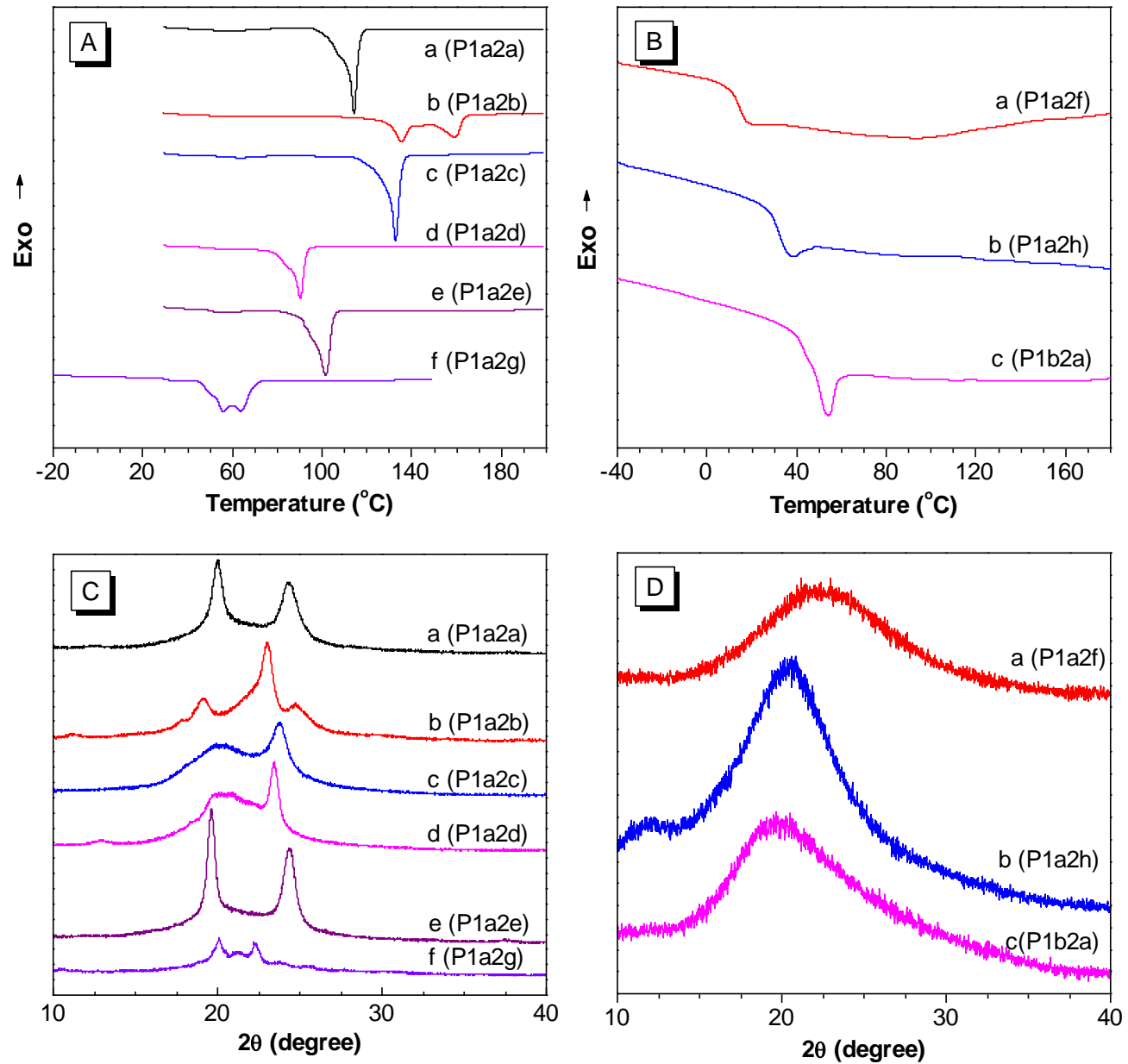

Figure 5. Differential scanning calorimetry (DSC) analysis of PVEEs: (A) crystalline polymers; (B) amorphous polymers. One-dimension wide-angle X-ray diffraction (1D-WAXD) of PVEEs: (C) crystalline polymers; (D) amorphous polymers. 
The thermal properties of the resultant PVEEs were also investigated by DSC, (Figure 5A and B). The polymers in Figure 5A exhibited melting peaks, indicating they are crystalline because of their flexible polymer chains. P1a2b and P1a2g showed two separated melting peaks probably due to the existence of defects in their crystals. No melting peaks were recorded in the DSC curves of P1a2f, P1a2h, and P1b2a, demonstrating that they are amorphous probably due to their irregular structures. Their glass transition temperatures $\left(T_{\mathrm{g}} \mathrm{s}\right)$ were observed at 14.7, 32.1 and $49.8{ }^{\circ} \mathrm{C}$, respectively. The melting enthalpies $\left(\Delta H_{\mathrm{m}} \mathrm{s}\right)$ of these polymers are listed in Table 6.

To determine the morphology of PVEEs, 1D-WAXD patterns were obtained. Figures 5C and 5D show 1D-WAXD profiles of the resultant polymers from P1a2a to P1b2a. P1a2f, P1a2h, and P1b2a in Figure 5D showed broad diffraction peaks, confirming the amorphous nature of these polymers. P1a2a-P1a2f and P1a2h exhibited sharp diffraction peaks, indicating that they have typical crystalline structures. ${ }^{45,46}$ The diffraction peaks were observed at $2 \theta=20.0^{\circ}$ and $24.3^{\circ}$ for P1a2a, $19.1^{\circ}, 23.1^{\circ}$, and $24.9^{\circ}$ for P1a2b, $23.8^{\circ}$ for P1a2c, $23.4^{\circ}$ for P1a2d, $19.6^{\circ}$ and $24.3^{\circ}$ for P1a2e, $20.1^{\circ}$ and $22.3^{\circ}$ for P1a2g, respectively. These WAXD results are consistent with DSC data.

Click polymerization of diphenols and diynes. To extend the scope of click polymerization, phenolic hydroxyl groups were used to replace alcoholic hydroxyl groups for reacting with diynes (Table S1). It was demonstrated that diphenols and diynes can be polymerized more efficiently even when the monomer concentration is 
only $0.1 \mathrm{M}$, revealing that DABCO-catalyzed click polymerization is not only applicable to alcoholic diols, but also to diphenols, thus providing a basis for further application of hydroxyl-diynes click polymerization.

Photoluminescene (PL) properties and applications. Thanks to the great functional tolerance of this hydroxyl-yne click polymerization, the typical AIE moiety, TPE, was introduced into polymer chains to endow the polymers (P1a2h and $\mathrm{P} \mathbf{1 a 2} \mathbf{j}$, Scheme S5) with AIE feature. ${ }^{47-49}$ Their emission behaviors were systematically investigated in THF/water mixtures with different water fractions $\left(f_{\mathrm{w}} \mathrm{s}\right)$ (Figure S6). The PL curves of P1a2h and P1a2j in THF solution are nearly parallel with the abscissa axis, illustrating the weak emission in pure THF. Their PL intensities increased gradually with increasing $f_{\mathrm{w}}$, and reached the highest level at a $f_{\mathrm{w}}$ of $90 \%$, which are 65 and 125-fold higher than that in THF, respectively, demonstrating that P1a2h and P1a2j are AIE-active. Because of its high emission in the aggregate state and quenching effect of nitro groups of explosives, the aggregates of P1a2h and P1a2j may be used as a fluorescence probe to detect explosives, which is important for homeland security and antiterrorism. ${ }^{50-52}$ Commercially available picric acid (PA) was used as an explosive model to test this possibility. The mixture of THF/water with a $f_{\mathrm{w}}$ of $90 \%$ was used as probe for both polymers. As depicted in Figure S7, PL intensities of aggregates of P1a2h and P1a2j decreased significantly upon the addition of PA into their aqueous solution, but the PL spectral profile remained unchanged, indicating the feasibility of such an application. 


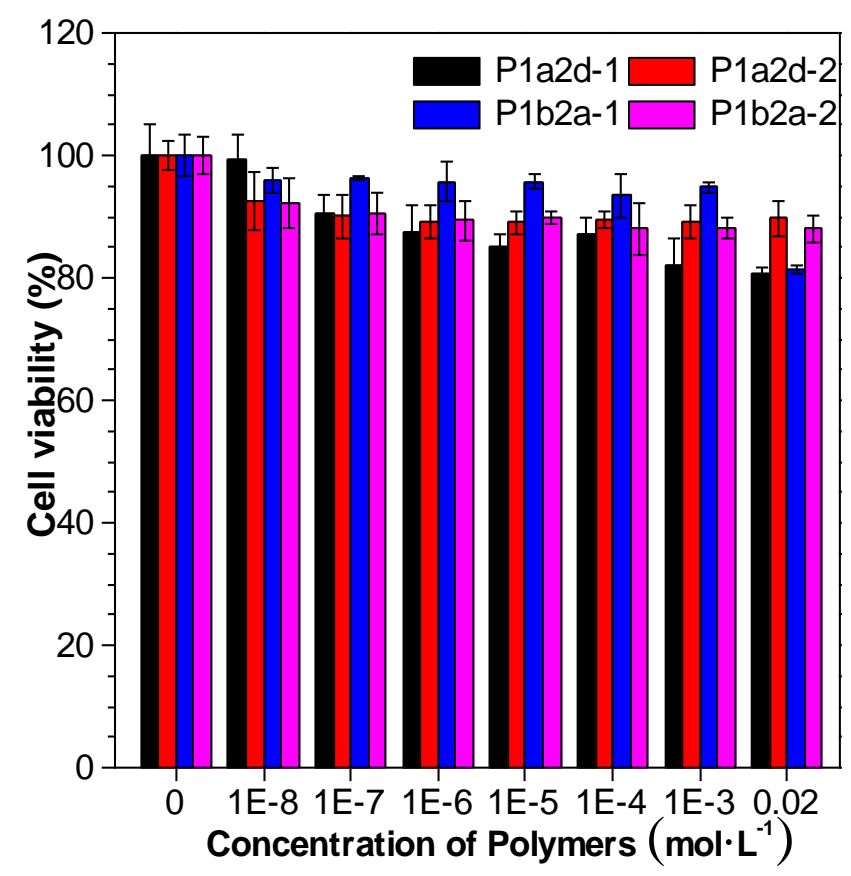

Figure 6. Cell viability of Hela cells in the presence P1a2d and P1b2a with different concentrations.

The resultant polymers may also have potential biomedical applications due to their degradability. ${ }^{40,53,54}$ The cytotoxicity, one of the most important properties for biomedical application, was thus evaluated for both crude and purified polymers (P1a2d and P1b2a) using a standard MTT cell viability assay. Herein, a crude polymer containing the base catalyst $\mathrm{DABCO}$ was used as a control. The results showed that the cell viabilities remain over $80 \%$ at an even polymer concentration of $0.02 \mathrm{M}$ for Hela cells, indicating the low cytotoxicity of PVEEs (Figure 6).

In summary, a more efficient metal-free click polymerization of diols and activated diynes was developed successfully under mild conditions. The polymers, PVEEs, with high molecular weights and good yields were prepared, and they possess good solubility and thermal stability. Depending on the flexibility of monomers, both semi-crystalline and amorphous polymers could be obtained. Thanks to the excellent 
functional group tolerance, the AIE-active TPE moieties could be introduced into polymers, endowing them with AIE features. The TPE-containing polymers may have potential applications for detecting explosives. Furthermore, these polymers may also be used in biomedical field due to their low cytotoxicity. The above results indicate that polymers obtained from this efficient metal-free click polymerization may be applied in various fields and this powerful hydroxyl-yne click react pave a way for facile saccharides modification, which is on-going in our group.

\section{ASSOCIATED CONTENT}

\section{Supporting Information}

The supporting information, including detailed synthetic routes to monomers, FT-IR spectra, ${ }^{1} \mathrm{H}$ and ${ }^{13} \mathrm{C}$ NMR spectra of P1a2b to P1b2a, and photophysical properties of $\mathrm{P} 1 \mathbf{a} 2 \mathbf{h}$ and $\mathrm{P} 1 \mathbf{a} 2 \mathbf{j}$ is available free of charge on the ACS publications website.

\section{AUTHOR INFORMATION}

\section{Corresponding Author}

*E-mail: msqinaj@scut.edu.cn (A.J.Q.).

\section{ORCID}

Anjun Qin: 0000-0001-7158-1808

Ben Zhong Tang: 0000-0002-0293-964X

\section{Notes}

The authors declare no competing financial interest.

\section{ACKNOWLEDGMENT}

This work was financially supported by the National Natural Science Foundation of 
China (21788102, 21525417, 21490571 and 51620105009), the Natural Science Foundation of Guangdong Province (2016A030312002, 2018A030313763 and 2019B030301003), the Fundamental Research Funds for the Central Universities (2015ZY013), and the Innovation and Technology Commission of Hong Kong (ITC-CNERC14S01).

\section{Reference:}

(1)Ghazarian, H.; Idoni, B.; Oppenheimer, S. B. A Glycobiology Review: Carbohydrates, Lectins and Implications in Cancer Therapeutics. Acta Histochem 2011, 113, 236-247.

(2)Davis, A. P.; Wareham, R. S. Carbohydrate Recognition through Noncovalent Interactions: A Challenge for Biomimetic and Supramolecular Chemistry. Angew. Chem. Int. Ed 1999, 38, 2978-2996.

(3)Seeberger, P. H.; Werz, D. B. Automated Synthesis of Oligosaccharides as a Basis for Drug Discovery. Nat. Rev. Drug. Discov. 2005, 4, 751-763.

(4)Seeberger, P. H.; Werz, D. B. Synthesis and Medical Applications of Oligosaccharides. Nature 2007, 446, 1046-1051.

(5)Cho, S.; Heo, G. S.; Khan, S.; Huang, J.; Hunstad, D. A.; Elsabahy, M.; Wooley, K. L. A Vinyl Ether-Functional Polycarbonate as a Template for Multiple Postpolymerization Modifications. Macromolecules 2018, 51, 3233-3242.

(6)Dove, 1. The Bittersweet Promise of Glycobiology. Nat. Biotechnol. 2001, 19, 913-917. 
(7)Gloster, T. M.; Vocadlo, D. J. Developing Inhibitors of Glycan Processing Enzymes as Tools for Enabling Glycobiology. Nat. Chem. Biol. 2012, 8, 683-694.

(8)Wu, C. Y.; Wong, C. H. Chemistry and Glycobiology. Chem. Commun. 2011, 47, 6201-6207.

(9)Pashkuleva, I.; Reis, R. L. Sugars: Burden or Biomaterials of the Future? J. Mater. Chem. 2010, 20, 8803.

(10)Thongsomboon, W.; Serra, D. O.; Possling, A.; Hadjineophytou, C.; Hengge, R.; Cegelski, L. Phosphoethanolamine Cellulose: A Naturally Produced Chemically Modified Cellulose. Science 2018, 359, 334-338.

(11)Lin, Y.-N.; Su, L.; Smolen, J.; Li, R.; Song, Y.; Wang, H.; Dong, M.; Wooley, K. L. Co-Assembly of Sugar-Based Amphiphilic Block Polymers to Achieve Nanoparticles with Tunable Morphology, Size, Surface Charge, and Acid-Responsive Behavior. Mater. Chem. Front. 2018, 2, 2230-2238.

(12)Forsyth, S. A.; MacFarlane, D. R.; Thomson, R. J.; von Itzstein, M. Rapid, Clean, and Mild O-Acetylation of Alcohols and Carbohydrates in an Ionic Liquid. Chem. Commun. 2002, 714-715.

(13)Dalpozzo, R.; De Nino, A.; Maiuolo, L.; Procopio, A.; Nardi, M.; Bartoli, G.; Romeo, R. Highly Efficient and Versatile Acetylation of Alcohols Catalyzed by Cerium(Iii) Triflate. Tetrahedron Lett. 2003, 44, 5621-5624.

(14)Procopio, A.; Dalpozzo, R.; De?Nino, A.; Maiuolo, L.; Russo, B.; Sindona, G. Erbium(Iii) Triflate as an Extremely Active Acylation Catalyst. Adv. Synth. Catal. 2004, 346, 1465-1470. 
(15)Bizier, N. P.; Atkins, S. R.; Helland, L. C.; Colvin, S. F.; Twitchell, J. R.; Cloninger, M. J. Indium Triflate Catalyzed Peracetylation of Carbohydrates. Carbohydr. Res. 2008, 343, 1814-1818.

(16)Gabrielli, L.; Calloni, I.; Donvito, G.; Costa, B.; Arrighetti, N.; Perego, P.; Colombo, D.; Ronchetti, F.; Nicotra, F.; Cipolla, L. Phosphatidylinositol 3-Phosphate Mimics Based on a Sulfoquinovose Scaffold: Synthesis and Evaluation as Protein Kinase B Inhibitors. Eur. J. Org. Chem. 2014, 2014, 5962-5967.

(17)Prajapti, S. K.; Nagarsenkar, A.; Babu, B. N. Tris(Pentafluorophenyl)Borane Catalyzed Acylation of Alcohols, Phenols, Amines, and Thiophenols under Solvent-Free Condition. Tetrahedron Lett. 2014, 55, 1784-1787.

(18)Filice, M.; Guisan, J. M.; Terreni, M.; Palomo, J. M. Regioselective Monodeprotection of Peracetylated Carbohydrates. Nat. Protoc. 2012, 7, 1783-1796.

(19)Walker, H. G., Jr.; Gee, M.; McCready, R. M. Complete Methylation of Reducing Carbohydrates. J. Org. Chem. 1962, 27, 2100-2102.

(20)Gurbuz, E. I.; Gallo, J. M.; Alonso, D. M.; Wettstein, S. G.; Lim, W. Y.; Dumesic, J. A. Conversion of Hemicellulose into Furfural Using Solid Acid Catalysts in Gamma-Valerolactone. Angew. Chem. Int. Ed. 2013, 52, 1270-1274.

(21)Cui, J.; Tan, J.; Deng, T.; Cui, X.; Zhu, Y.; Li, Y. Conversion of Carbohydrates to Furfural Via Selective Cleavage of the Carbon-Carbon Bond: The Cooperative Effects of Zeolite and Solvent. Green Chem. 2016, 18, 1619-1624.

(22)Hou, Q.; Li, W.; Zhen, M.; Liu, L.; Chen, Y.; Yang, Q.; Huang, F.; Zhang, S.; Ju, M. An Ionic Liquid-Organic Solvent Biphasic System for Efficient Production of 
5-Hydroxymethylfurfural from Carbohydrates at High Concentrations. RSC Adv. 2017, 7, 47288-47296.

(23)Cao, Z.; Fan, Z.; Chen, Y.; Li, M.; Shen, T.; Zhu, C.; Ying, H. Efficient Preparation of 5-Hydroxymethylfurfural from Cellulose in a Biphasic System over Hafnyl Phosphates. Applied Catalysis B: Environmental 2019, 244, 170-177.

(24)Zhang, J.; Lin, L.; Zhang, J.; Shi, J. Efficient Conversion of D-Glucose into D-Sorbitol over Mcm-41 Supported Ru Catalyst Prepared by a Formaldehyde Reduction Process. Carbohydr. Res. 2011, 346, 1327-1332.

(25)Liebert, T.; Hänsch, C.; Heinze, T. Click Chemistry with Polysaccharides. Macromol. Rapid Commun. 2006, 27, 208-213.

(26)Hetzer, M.; Chen, G.; Barner-Kowollik, C.; Stenzel, M. H. Neoglycopolymers Based on 4-Vinyl-1,2,3-Triazole Monomers Prepared by Click Chemistry. Macromol. Biosci. 2010, 10, 119-126.

(27)Dumont, A.; Malleron, A.; Awwad, M.; Dukan, S.; Vauzeilles, B. Click-Mediated Labeling of Bacterial Membranes through Metabolic Modification of the Lipopolysaccharide Inner Core. Angew. Chem. Int. Ed 2012, 51, 3143-3146.

(28)He, X. P.; Zeng, Y. L.; Zang, Y.; Li, J.; Field, R. A.; Chen, G. R. Carbohydrate Cuaac Click Chemistry for Therapy and Diagnosis. Carbohydr. Res. 2016, 429, 1-22. (29)Tiwari, V. K.; Mishra, B. B.; Mishra, K. B.; Mishra, N.; Singh, A. S.; Chen, X. Cu-Catalyzed Click Reaction in Carbohydrate Chemistry. Chem. Rev. 2016, 116, 3086-3240.

(30)Yang, H.; Zuo, Y.; Zhang, J.; Song, Y.; Huang, W.; Xue, X.; Jiang, Q.; Sun, A.; 
Jiang, B. Phosphazene-Catalyzed Oxa-Michael Addition Click Polymerization. Polym. Chem. 2018, 9, 4716-4723.

(31)Qin, A.; Tang, L.; Lam, J. W. Y.; Jim, C. K. W.; Yu, Y.; Zhao, H.; Sun, J.; Tang, B.

Z. Metal - Free Click Polymerization: Synthesis and Photonic Properties of Poly(Aroyltriazole)S. Adv. Funct. Mater. 2009, 19, 1891-1900.

(32)Wu, H.; Dong, W.; Wang, Z.; Yao, B.; Chen, M.; Sun, J.; Qin, A.; Tang, B. Z. An Air-Stable Supported $\mathrm{Cu}(\mathrm{I})$ Catalyst for Azide-Alkyne Click Polymerization. Sci. China Chem. 2015, 58, 1748-1752.

(33)Jim, C. K. W.; Qin, A.; Lam, J. W. Y.; Mahtab, F.; Yu, Y.; Tang, B. Z. Metal-Free Alkyne Polyhydrothiolation: Synthesis of Functional Poly(Vinylenesulfide)S with High Stereoregularity by Regioselective Thioclick Polymerization. Adv. Funct. Mater. 2010, 20, 1319-1328.

(34)Yao, B.; Mei, J.; Li, J.; Wang, J.; Wu, H.; Sun, J. Z.; Qin, A.; Tang, B. Z. Catalyst-Free Thiol-Yne Click Polymerization: A Powerful and Facile Tool for Preparation of Functional Poly(Vinylene Sulfide)S. Macromolecules 2014, 47, 1325-1333.

(35)Yao, B.; Hu, T.; Zhang, H.; Li, J.; Sun, J. Z.; Qin, A.; Tang, B. Z. Multi-Functional Hyperbranched Poly(Vinylene Sulfide)S Constructed Via Spontaneous Thiol-Yne Click Polymerization. Macromolecules 2015, 48, 7782-7791. (36)He, B. Z.; Zhen, S. J.; Wu, Y. W.; Hu, R. R.; Zhao, Z. J.; Qin, A. J.; Tang, B. Z. Cu(I)-Catalyzed Amino-Yne Click Polymerization. Polym. Chem. 2016, 7, 7375-7382. 
(37)He, B.; Su, H.; Bai, T.; Wu, Y.; Li, S.; Gao, M.; Hu, R.; Zhao, Z.; Qin, A.; Ling, J.; Tang, B. Z. Spontaneous Amino-Yne Click Polymerization: A Powerful Tool toward Regio- and Stereospecific Poly(Beta-Aminoacrylate)S. J. Am. Chem. Soc. 2017, 139, $5437-5443$.

(38)Zhang, Y.; Lam, J. W. Y.; Tang, B. Z. Palladium-Catalyzed Alkyne Polyannulation of Diphenols and Unactivated Internal Diynes: A New Synthetic Route to Functional Heterocyclic Polymers. Polym. Chem. 2016, 7, 330-338.

(39)Wang, J.; Li, B.; Xin, D.; Hu, R.; Zhao, Z.; Qin, A.; Tang, B. Z. Superbase Catalyzed Regio-Selective Polyhydroalkoxylation of Alkynes: A Facile Route Towards Functional Poly(Vinyl Ether)S. Polym. Chem. 2017, 8, 2713-2722.

(40)Shi, Y.; Bai, T.; Bai, W.; Wang, Z.; Chen, M.; Yao, B.; Sun, J. Z.; Qin, A.; Ling, J.;

Tang, B. Z. Phenol-Yne Click Polymerization: An Efficient Technique to Facilely Access Regio- and Stereoregular Poly(Vinylene Ether Ketone)S. Chem. Eur. J. 2017, 23, 10725-10731.

(41)Chen, Y.; He, B.; Qin, A.; Tang, B. Z. Recyclable Cu Nanoparticle Catalyzed Azide-Alkyne Click Polymerization. Sci. China Chem. 2019, 62, 1017-1022.

(42)Hu, R.; Chen, X.; Zhou, T.; Si, H.; He, B.; Kwok, R. T. K.; Qin, A.; Tang, B. Z. Lab-in-Cell Based on Spontaneous Amino-Yne Click Polymerization. Sci. China Chem. 2019, 62, 1198-1203.

(43)Tejedor, D.; Álvarez-Méndez, S. J.; López-Soria, J. M.; Martín, V. S.; García-Tellado, F. A Robust and General Protocol for the Lewis-Base-Catalysed Reaction of Alcohols and Alkyl Propiolates. Eur. J. Org. Chem. 2014, 2014, 198-205. 
(44)Kuroda, H.; Tomita, I.; Endo, T. A Novel Polyaddition of Diols with Bifunctional Acetylenes Having Electron-Withdrawing Groups. Macromolecules 1995, 28, 433-436.

(45)Xu, Y.-C.; Zhou, H.; Sun, X.-Y.; Ren, W.-M.; Lu, X.-B. Crystalline Polyesters from $\mathrm{Co} 2$ and 2-Butyne Via A-Methylene-B-Butyrolactone Intermediate. Macromolecules 2016, 49, 5782-5787.

(46)Yue, T.-J.; Ren, W.-M.; Liu, Y.; Wan, Z.-Q.; Lu, X.-B. Crystalline Polythiocarbonate from Stereoregular Copolymerization of Carbonyl Sulfide and Epichlorohydrin. Macromolecules 2016, 49, 2971-2976.

(47)Hu, R.; Kang, Y.; Tang, B. Z. Recent Advances in Aie Polymers. Polym. J. 2016, $48,359-370$.

(48)Qin, A.; Lam, J. W. Y.; Tang, B. Z. Luminogenic Polymers with Aggregation-Induced Emission Characteristics. Prog. Polym. Sci. 2012, 37, 182-209. (49)Huang, Y.; Chen, P.; Wei, B.; Hu, R.; Tang, B. Z. Aggregation-Induced Emission-Active Hyperbranched Poly(Tetrahydropyrimidine) S Synthesized from Multicomponent Tandem Polymerization. Chin. J. Polym. Sci. 2019, 37, 428-436.

(50)He, B.; Wu, Y.; Qin, A.; Tang, B. Z. Copper-Catalyzed Electrophilic Polyhydroamination of Internal Alkynes. Macromolecules 2017, 50, 5719-5728.

(51)Salinas, Y.; Martinez-Manez, R.; Marcos, M. D.; Sancenon, F.; Costero, A. M.; Parra, M.; Gil, S. Optical Chemosensors and Reagents to Detect Explosives. Chem. Soc. Rev. 2012, 41, 1261-1296.

(52)Chong, K. C.; Hu, F.; Liu, B. Aiegen Bioconjugates for Specific Detection of 
Disease-Related Protein Biomarkers. Mater. Chem. Front. 2019, 3, 12-24.

(53)Vroman, I.; Tighzert, L. Biodegradable Polymers. Materials 2009, 2, 307-344.

(54)Delplace, V.; Nicolas, J. Degradable Vinyl Polymers for Biomedical Applications.

Nat Chem 2015, 7, 771-784. 
Table of Content

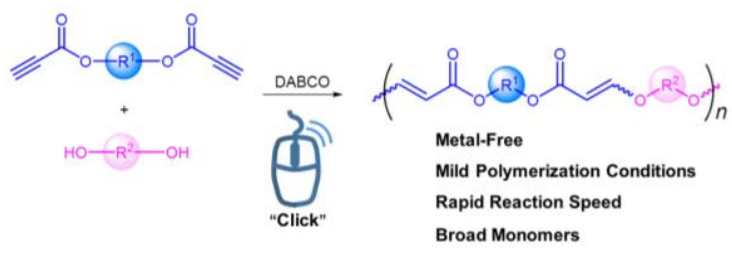

